TITLE:

\title{
Microscopic analysis of saltation of particles on an obliquely oscillating plate
}

$\operatorname{AUTHOR}(\mathrm{S})$ :

Kobayakawa, Murino; Yasuda, Masatoshi; Matsusaka, Shuji

\section{CITATION:}

Kobayakawa, Murino ...[et al]. Microscopic analysis of saltation of particles on an obliquely oscillating plate. Advanced Powder Technology 2014, 25(6): 1845-1853

\section{ISSUE DATE:}

2014-11

URL:

http://hdl.handle.net/2433/196047

\section{RIGHT:}

(c) 2014 The Society of Powder Technology Japan. NOTICE: this is the author's version of a work that was accepted for publication in Advanced Powder Technology. Changes resulting from the publishing process, such as peer review, editing, corrections, structural formatting, and other quality control mechanisms may not be reflected in this document. Changes may have been made to this work since it was submitted for publication. A definitive version was subsequently published in Advanced Powder Technology, 25(6), 2014 doi:10.1016/i.apt.2014.07.016; This is not the published version. Please cite only the published version.; この論文は出版社版でありません。引用の際には出版社版 をご確認ご利用ください。 


\title{
Microscopic analysis of saltation of particles on an obliquely oscillating plate
}

Murino Kobayakawa, Masatoshi Yasuda, Shuji Matsusaka*

Department of Chemical Engineering, Kyoto University, Kyoto 615-8510, Japan

* Corresponding author. E-mail address: matsu@cheme.kyoto-u.ac.jp (S. Matsusaka)

\begin{abstract}
This paper presents a microscopic analysis of the saltation of particles on an obliquely oscillating plate driven by sine waves with an amplitude on the order of tens of micrometers and a frequency on the order of hundreds of hertz. To examine the effect of the diameter of a particle on its motion, the trajectories and velocities of different-sized particles, from 0.5 to $500 \mu \mathrm{m}$ in mass median diameter, are analyzed using images captured by a high-speed microscope camera. The results show that larger particles bounce higher, whereas smaller particles easily agglomerate and bounce only slightly, owing to the low restitution caused by their loosely packed structure. In addition, larger particles bounce forward and backward repeatedly, while the agglomerated particles always bounce forward, and consequently have the highest transport velocity among these particles. The particle motion and the transport velocity can be explained by a theoretical probability model.
\end{abstract}

Keywords: Oblique oscillation; Fine particle; Saltation; Restitution coefficient; Fluid resistance

\section{Introduction}

The energy input from an oscillating surface can induce fluidization of particles. Through experiments and simulations for non-cohesive, coarse particles under vibration, unusual particle behaviors have been observed, e.g., convection [1-3], bubbling [4-6], and segregation [7-9]. More recently, using cohesive fine particles, vigorous bubbling caused by vibration-induced air inflow was demonstrated [10]. Such particle fluidization under vibration has been used for numerous applications, such as fluidized beds [11,12], conveyors [13,14], micro-feeders [15,16], and evaluation methods for powder flowability [17-19].

As one of the simplest systems of particle fluidization under vibration, one-dimensional motion analysis of particles bouncing on a vertically oscillating surface has been conducted, both experimentally and numerically [20-23]. The fluid state of the particles is influenced by the balance between the input of vibrational energy and its dissipation due to inelastic collisions and friction. Luding et al. found that the transition from a fluidized state where the particles move individually to a condensed state where the particles move as a particle bed depends on vibration acceleration, number of particles, and the coefficient of restitution [20,21]. However, the effects of particle size on the fluid state have not been studied fully. In industry, a vibrating conveyor, i.e., an oblique oscillating trough inducing two-dimensional motion of a particle bed, is used for the transport of solid materials. In this system, the energy input through the 
oscillating trough sufficiently dissipates owing to friction of particles; thus, the particles behave as a perfectly inelastic bed.

Although many studies on the dynamics of particles under vibration have been conducted, there have been few reports on the two-dimensional motion of individual particles on an obliquely oscillating plate, where the plate can induce the more significant differences in the motion of the different-sized particles than onedimensional vertical oscillating plate. In particular, there have been few studies on fine particles, because fine particles exhibit complicated behaviors owing to their adhesive and cohesive forces and fluid resistance. However, studies of fine particles are necessary, because there are many applications that use their unique size-dependent electric, magnetic, mechanical, optical, and chemical properties [24].

In this paper, the saltation of particles from 0.5 to $500 \mu \mathrm{m}$ in mass median diameter on an obliquely oscillating plate is studied. Their trajectories and velocities are analyzed from images captured by a highspeed microscope camera, and the effect of particle diameter on the motion is discussed. Furthermore, the transport velocities of the particles are evaluated.

\section{Experimental}

Fig. 1 shows a schematic diagram of the experimental setup. A metal plate $\left(15 \times 15 \mathrm{~mm}^{2}\right)$ made of stainless steel (SUS304) was mounted on a shock absorber. The plate was vibrated horizontally and vertically by piezoelectric vibrators. The signals applied to the vibrators were sine waves with a frequency of $280 \mathrm{~Hz}$ and the phase difference between the waves was zero. The vibration amplitude could be adjusted by the applied voltage. The vibrators were controlled by a vibration control system (VST-01, IMP. Co., Ltd.).

Different-sized alumina particles, with a mass median diameter $D_{p 50}$ from 0.5 to $500 \mu \mathrm{m}$, were used in the experiments: (1) irregularly shaped particles, $D_{p 50}=0.5 \mu \mathrm{m}$ (Fujimi Incorporated), (2) spherical particles, $D_{p 50}=5 \mu \mathrm{m}$ (Showa Denko K.K.), (3) spherical particles, $D_{p 50}=50 \mu \mathrm{m}$ (Showa Denko K.K.), and (4) spherical particles, $D_{p 50}=500 \mu \mathrm{m}$ (Taimei Chemicals Co., Ltd.). These particles were dried at $120^{\circ} \mathrm{C}$ over $24 \mathrm{~h}$ and cooled down to room temperature in a desiccator. The particles were distributed on the metal plate through a sieve. To avoid collisions between particles, the area covered by the particles was less than $0.5 \%$ of the total surface area.

The plate and the particles were illuminated by metal halide lamps (Smita LS-M250), and observed through a high-speed microscope camera with a resolution of $1 \mu \mathrm{m}$ (Fastcam-Max, Photron, Ltd.). The images were recorded at a rate of 3000 or 6000 frames per second (fps) and analyzed via digital image processing (Dipp-Motion 2D, Detect Co., Ltd). All the experiments were conducted at $20 \pm 2{ }^{\circ} \mathrm{C}$, and the relative humidity was controlled at $30-40 \%$ to avoid disturbances caused by liquid bridge forces.

\section{Results and discussion}

\subsection{Two-dimensional vibration of the plate}


Figs. 2(a) and (b) show the horizontal and vertical displacements of the oscillating plate as a function of time elapsed; these were obtained from the images captured by the high-speed microscope camera at a frame rate of $6000 \mathrm{fps}$. The experimental results indicate that the plate was sinusoidally oscillated with an amplitude of $A=35 \mu \mathrm{m}$. The angular velocity was $1760 \mathrm{~s}^{-1}$, and the period of the cycle was $3.6 \mathrm{~ms}$, which corresponded to a vibration frequency of $f=280 \mathrm{~Hz}$. From the amplitude and frequency, the maximum vibration velocity was determined to be $62 \mathrm{~mm} / \mathrm{s}$. These two vibration waves were synchronized. Fig. 3 shows the Lissajous figure of the oscillating plate over ten cycles. The two synchronized sine waves formed an inclined linear vibration at a $45^{\circ}$ angle from horizontal, showing that the repeatability was sufficiently high.

\subsection{Effect of particle diameter on particle motion}

For $D_{p 50}=500 \mu \mathrm{m}$ and $50 \mu \mathrm{m}$, the obliquely oscillating plate induced particle saltation. For $D_{p 50}=5 \mu \mathrm{m}$, the particles adhered to the oscillating plate and did not saltate owing to their adhesive forces. The particles with $D_{p 50}=0.5 \mu \mathrm{m}$ formed agglomerated particles owing to van der Waals force after passing though the sieve. The morphology of the agglomerated particles was observed through a scanning electron microscope (VE9800, Keyence Corp.). Fig. 4(a) shows the SEM image of the agglomerated particle. The agglomerated particle was almost spherical. In addition, the magnified image is shown in Fig. 4(b). From this figure, it is observed that the agglomerated particle had a loosely packed structure consisting of the small primary particles. The volume-based size distribution of the agglomerated particles was characterized with the circle-equivalent diameter, showing that the median diameter was $D_{a g 50}=150 \mu \mathrm{m}$. The agglomerated particles also saltated; however, further agglomeration or disintegration was not observed in this system.

Here, to clarify the relationship between the motion and the physical properties of the particles with $D_{p 50}$ $=500 \mu \mathrm{m}, 50 \mu \mathrm{m}$ and $0.5 \mu \mathrm{m}\left(D_{a g 50}=150 \mu \mathrm{m}\right)$, the properties, i.e., particle density $\rho_{p}$, particle weight $m_{p}$, coefficient of restitution $e$ and coefficient of friction $\mu$ of particle-plate collision, were measured in the preliminary tests, as summarized in Table 1. For $D_{p 50}=0.5 \mu \mathrm{m}$, the properties of the agglomerated particles are shown instead of the primary particles. The coefficient of restitution $e$ was obtained as the ratio of the vertical velocities before and after collision. Coefficient of friction $\mu$ was determined by a general method $[25,26]$.

Fig. 5 shows snapshots of the particle saltation for $D_{p 50}=500 \mu \mathrm{m}, 50 \mu \mathrm{m}$, and $0.5 \mu \mathrm{m}\left(D_{a g 50}=150 \mu \mathrm{m}\right)$, which were captured by the high-speed camera at the same scale. The $x$ and $y$ coordinates are defined by setting the $x$-axis and $y$-axis tangential and normal (upward) to the plate, respectively. Forward and backward directions indicate positive and negative directions of the $x$-axis. In Fig. 5(a), a single particle, $D_{p 50}=500 \mu \mathrm{m}$, was bouncing on the oscillating plate. From Fig. 5(b), it was observed that many single particles, $D_{p 50}=50 \mu \mathrm{m}$, saltated at a height range several times lower than that for $D_{p 50}=500 \mu \mathrm{m}$. The 
difference can be attributed to fluid resistance. Details of this difference are discussed in Section 3.4. In Fig. 5(c), the agglomerated particles consisting of primary particles with $D_{p 50}=0.5 \mu \mathrm{m}$ bounced only slightly because of the low restitution of their loosely packed structure.

Fig. 6 shows the trajectories of the particles for $D_{p 50}=500 \mu \mathrm{m}, 50 \mu \mathrm{m}$, and $0.5 \mu \mathrm{m}\left(D_{a g}=150 \mu \mathrm{m}\right)$, which were tracked by digital image processing. The value of zero in the vertical displacement indicates the center of the oscillating surface. The trajectories are drawn assuming zero-radius particles. Circles in this figure denote particle-plate collisions, where the displacements are not always zero because the surface is oscillating. The height and direction of each bounce changed depending on the state of the particle-plate collision. Fig. 6(a) shows that a particle for $D_{p 50}=500 \mu \mathrm{m}$ had three larger bounces moving forward (solid line) and three smaller bounces moving backward (dashed line). The bounce height range of the particle was up to approximately $5 \mathrm{~mm}$ and the horizontal distance of each bounce was in a range from -0.8 to +1.5 mm. Fig. 6(b) shows that a particle with $D_{p 50}=50 \mu \mathrm{m}$ had five larger forward bounces and one smaller backward bounce. The particle reached a height of $1.1 \mathrm{~mm}$, and the horizontal distances were in the range of $-0.1-0.8 \mathrm{~mm}$. The comparison between Fig. 6 (a) and (b) shows that the smaller particle had the smaller bounces with asymmetric trajectories due to the effect of fluid resistance during flight. In Fig. 6(c), an agglomerated particle ( $D_{p 50}=0.5 \mu \mathrm{m}, D_{a g}=150 \mu \mathrm{m}$ ) always bounced forward, where the height was up to $0.16 \mathrm{~mm}$ and the horizontal distances were in the range of $0-0.4 \mathrm{~mm}$. The agglomerated particle bounced only slightly because of the low coefficient of restitution as a result of larger energy dissipation during collisions (see Table 1).

Fig. 7 shows the cumulative distributions of the bounce height for three different-sized particles, which were calculated from 200 bounces including the forward and backward bounces. The height distributions of particles with $D_{p 50}=500 \mu \mathrm{m}, 50 \mu \mathrm{m}$, and $0.5 \mu \mathrm{m}\left(D_{a g 50}=150 \mu \mathrm{m}\right)$ had ranges of 0-8 mm, 0-2 mm, and $0-0.3 \mathrm{~mm}$, respectively, and median heights of $2 \mathrm{~mm}, 0.5 \mathrm{~mm}$, and $0.1 \mathrm{~mm}$. The range of the particles with $D_{p 50}=50 \mu \mathrm{m}$ was lower than that of the particles with $D_{p 50}=500 \mu \mathrm{m}$ owing to the effect of the fluid resistance during flight. The particles with $D_{a g 50}=150 \mu \mathrm{m}$ had the lowest height range because of nearly perfect inelastic collisions.

Fig. 8 shows the cumulative distributions of the bounce distance for three different-sized particles. The positive and negative values of the distances indicate forward and backward bounces, respectively. The distance distributions of particles with $D_{p 50}=500 \mu \mathrm{m}, 50 \mu \mathrm{m}$, and $0.5 \mu \mathrm{m}\left(D_{a g 50}=150 \mu \mathrm{m}\right)$ had ranges of $-2-4 \mathrm{~mm},-0.3-1.2 \mathrm{~mm}$, and $0-0.6 \mathrm{~mm}$ and median distances of $0.6 \mathrm{~mm}, 0.3 \mathrm{~mm}$, and $0.2 \mathrm{~mm}$. The range decreases with decreasing bounce height due to shorter time intervals between successive collisions. The ratios of the backward bounces to the total number of bounces for $D_{p 50}=500 \mu \mathrm{m}, 50 \mu \mathrm{m}$, and $D_{a g 50}=150$ $\mu \mathrm{m}$ are $0.3,0.1$, and 0 , respectively. The mechanism for the difference in the ratio is discussed in Section 3.5 .

\subsection{Analysis of particle-plate collision}


To examine the effect of the state of the particle-plate collisions on the horizontal direction of motion of a rebounding particle, the trajectories of the particles in Fig. 6 were converted to vertical displacements as a function of time elapsed.

Fig. 9 shows the vertical displacements as a function of time elapsed for $D_{p 50}=500 \mu \mathrm{m}, 50 \mu \mathrm{m}$, and 0.5 $\mu \mathrm{m}\left(D_{a g 50}=150 \mu \mathrm{m}\right)$. The thick solid lines, thin solid lines, and dashed lines in this figure indicate the oscillating plate, particles moving forward, and particles moving backward, respectively. In Fig. 9 (a), the particle, $D_{p 50}=500 \mu \mathrm{m}$, collided with the plate in intervals of 22-62 ms. To quantify the state of each particle-plate collision, the magnified figures are shown under Fig. 9(a). The particle collided with the plate moving downward at 32, 170, and $210 \mathrm{~ms}$ and rebounded backward. On the other hand, the particle colliding with the plate moving upward at 62 and 110 ms rebounded forward. The heights of the forward bounces were higher than those of the backward bounces.

These differences are explained as follows: when the plate is moving upward and downward, the plate is moving forward and backward, respectively, because the vibration waves in two directions are synchronized. Therefore, when the particle collides with the plate moving downward, the particle experiences a friction force acting in a backward direction and a lower rebound force. On the other hand, the particle colliding with the plate moving upward experiences a friction force acting in a forward direction and a higher rebound force, i.e., the direction of motion and bounce height are controlled by the state of the particle-plate collision. In Fig. 9(b), the particle, $D_{p 50}=50 \mu \mathrm{m}$, collided with the plate in intervals of 10$30 \mathrm{~ms}$. The behavior of the particle was similar to that for $D_{p 50}=500 \mu \mathrm{m}$, except for the bounce heights and the number of backward motions. In Fig. 9(c), the agglomerated particle ( $\left.D_{p 50}=0.5 \mu \mathrm{m}, D_{a g 50}=150 \mu \mathrm{m}\right)$ rebounded in intervals of 3-10 ms and always moved forward because the particles did not collide with the plate moving downward.

\subsection{Analysis of particle velocity during each bounce}

Fig. 10 shows the vertical velocities as a function of time elapsed for $D_{p 50}=500 \mu \mathrm{m}, 50 \mu \mathrm{m}$, and $0.5 \mu \mathrm{m}$ $\left(D_{a g 50}=150 \mu \mathrm{m}\right)$. The values were obtained from the trajectories in Figs. 6(a)-(c). The instantaneous velocities were obtained from the time derivatives of the positions between two successive images (time interval: $0.33 \mathrm{~ms}$ ). In Fig. 10(a), the vertical velocity of a particle, $D_{p 50}=500 \mu \mathrm{m}$, had a range from -300 to $+300 \mathrm{~mm} / \mathrm{s}$. The velocity of the particle reached a maximum value at collision with the plate and decreased linearly with time elapsed during each bounce. This means that the fluid resistance has a negligible effect on the movement of the particle compared with gravity. From Fig. 10(b), it was found that the velocity of the particle, $D_{p 50}=50 \mu \mathrm{m}$ decreased nonlinearly with time elapsed and that the absolute value of the incident velocity was smaller than that of the rebound velocity because the kinetic energy dissipated as a result of fluid resistance. As a result, the velocity also had a lower range $(-120-180 \mathrm{~mm} / \mathrm{s})$ 
than that for $D_{p 50}=500 \mu \mathrm{m}$. In Fig. 10(c), the velocity of the agglomerated particle ( $D_{p 50}=0.5 \mu \mathrm{m}, D_{a g 50}=$ $150 \mu \mathrm{m}$ ) ranged from -45 to $60 \mathrm{~mm} / \mathrm{s}$. This range was within the range of the oscillating plate velocity, i.e. -62 to $62 \mathrm{~mm} / \mathrm{s}$. This is because the collision between the agglomerated particle and the plate was almost perfectly inelastic.

Fig. 11 shows the horizontal velocities of the particles, which were obtained from the trajectories in Fig. 6. In Fig. 11(a), the horizontal velocity of the particle, $D_{p 50}=500 \mu \mathrm{m}$, had a range from -20 to $40 \mathrm{~mm} / \mathrm{s}$. The velocity significantly changed at the particle-plate collision. When the particle was in the air, the velocity was almost constant because the effect of fluid resistance was small. In Fig. 11(b), the horizontal velocity of the particle, $D_{p 50}=50 \mu \mathrm{m}$, had a range from -25 to $40 \mathrm{~mm} / \mathrm{s}$ and its absolute value obviously decreased during each bounce owing to the effect of fluid resistance. In Fig. 11(c), the velocity of the agglomerated particle had a range from 10 to $50 \mathrm{~mm} / \mathrm{s}$. The agglomerated particle was also susceptible to the effect of fluid resistance. This is because the gravity of the agglomerated particles is rather small, owing to their loosely packed structure.

To discuss the generation and dissipation of kinetic energy during saltation, the ratio of rebound velocity $v_{n r}$ to incident velocity $v_{n i}$ at $n$th collision, and the ratio of incident velocity $v_{(n+1) i}$ at $n+1$ th collision to rebound velocity $v_{n r}$ at $n$th collision were calculated from the results shown in Figs. 10 and 11. Table 2 shows the values of the two ratios for three different-sized particles. The ranges of the values were determined by the means and the standard deviations of sets of data. A value of unity means that kinetic energy is conserved. For $D_{p 50}=500 \mu \mathrm{m}$ and $50 \mu \mathrm{m}$, the velocity ratios after each collision were distributed around unity, whereas the most of the values for the agglomerated particle $\left(D_{p 50}=0.5 \mu \mathrm{m}, D_{a g 50}=150 \mu \mathrm{m}\right)$ were larger than unity. This difference is related to the collision probability depending on the phase angle of the oscillating plate which is discussed in Section 3.5. The velocity ratios during each bounce were unity for $D_{p 50}=500 \mu \mathrm{m}$, while those for $D_{p 50}=50 \mu \mathrm{m}$ and $D_{p 50}=0.5 \mu \mathrm{m}\left(D_{a g 50}=150 \mu \mathrm{m}\right)$ were less than unity; i.e. kinetic energy was dissipated by the fluid resistance.

\subsection{Collision probability depending on the phase angle of the oscillating plate}

As mentioned in Section 3.2, the ratio of the backward bounces to all the bounces for $D_{p 50}=500 \mu \mathrm{m}$ was higher than that for $D_{p 50}=50 \mu \mathrm{m}$ and the agglomerated particle with $D_{a g 50}=150 \mu \mathrm{m}$ always bounced forward, i.e., the ratio was zero. The difference in the ratio can be attributed to the difference in the bounce height. Here, we need to consider two factors. First, higher bounces cause larger impulses at particle-plate collisions. The larger impulses induce larger horizontal forces in this system using the obliquely oscillating plate and consequently change the horizontal moving velocity of the particle. Second, the collision probability depends on both the vertical velocity of the incident particle and the velocity of the oscillating plate. When the particle velocity is lower than the plate velocity moving downward, the particle cannot approach the plate; as a result, the particle cannot collide with the plate. Therefore, the collision probability 
depends on the phase angle of the oscillating plate.

Fig. 12 illustrates the vertical displacements of the oscillating plate as a function of phase angle $\varphi$ and the movement of incident particles with two different vertical velocities. In this analysis, it is assumed that the particles are fed downward at constant time intervals and the vertical velocity of the incident particles is constant until the particles collide with the plate. As shown in Fig. 12(a), when the incident particles are fast enough, they can collide with the oscillating plate at all phase angles. However, slow incident particles increase the probability of particle collision with the plate moving upward, i.e., the particles can collide in a range between the two critical phase angles $\varphi_{0}$ and $\varphi_{1}$ (see Fig. 12(b)). Therefore, these critical values will depend on the bounce height [27-30].

The collision probability as a function of the phase angle for a one-dimensional vertical oscillating plate has already been studied $[27,28,30]$. When the vertical velocity of the incident particle is greater than that of the plate moving downward, the probability density function of the collision $P(\varphi)$ for the sinusoidally oscillating plate is expressed by the following equation [27]:

$$
P(\varphi)=\frac{1}{2 \pi}\left[1-\left.\left(\frac{A \omega}{V}\right) \cos \varphi\right|_{\rfloor} \quad(0<\varphi<2 \pi)\right.
$$

where $A$ is the vertical amplitude of the oscillating plate, $\omega$ is the angular velocity $(=2 \pi f)$, and $V$ is the vertical velocity of the incident particle. For $V<A \omega, P(\varphi)$ is expressed as [27]:

$$
\begin{aligned}
& P(\varphi)=\frac{1}{2 \pi}\left[1-\left.\left(\frac{A \omega}{V}\right) \cos \varphi\right|_{1}\right] \quad\left(\varphi_{0}<\varphi<\varphi_{1}\right) \\
& P(\varphi)=0 \quad\left(0<\varphi<\varphi_{0}, \varphi_{1}<\varphi<2 \pi\right)
\end{aligned}
$$

The two critical phase angles $\varphi_{0}$ and $\varphi_{1}$ are determined by the following geometrical relations:

$$
\begin{aligned}
& \cos \left(2 \pi-\varphi_{1}\right)=\frac{V}{A \omega} \\
& \sin \varphi_{0}+\sin \left(2 \pi-\varphi_{1}\right)=\left\{\varphi_{0}+\left(2 \pi-\varphi_{1}\right)\right\} \frac{V}{A \omega}
\end{aligned}
$$

A value of integral of the probability density function $P(\varphi)$ in a region of phase angle is the occurrence probability of collision in the region under the assumption that the particles are fed downward at constant time intervals.

Fig. 13 shows the analytical results of the collision of the particles with the oscillating plate, i.e., the vertical displacement of the plate as a function of phase angle and the relationship between the probability density of the collision and phase angle as a parameter of vertical incident velocity, which were calculated using Eqs. (1) and (2) under the experimental conditions ( $\left.A=35 \mu \mathrm{m}, \omega=1760 \mathrm{~s}^{-1}\right)$. The absolute incident velocities of the particles for $D_{p 50}=500 \mu \mathrm{m}, 50 \mu \mathrm{m}$, and $0.5 \mu \mathrm{m}\left(D_{a g 50}=150 \mu \mathrm{m}\right)$ were in the ranges of $100-300 \mathrm{~mm} / \mathrm{s}, 30-120 \mathrm{~mm} / \mathrm{s}$, and 20-45 mm/s, respectively (see Figs. 10(a)-(c)). From Fig. 13, it is found that for $V=300 \mathrm{~mm} / \mathrm{s}$, the variation of the collision probability density as a function of the phase angle is rather small. For $V=44.6 \mathrm{~mm} / \mathrm{s}$, the particle can collide with the plate for $0.50 \pi<\varphi<1.76 \pi \mathrm{rad}$. It is worth 
noting that the collision probability density is discontinuous at the smaller critical phase angle, i.e., $0.50 \pi$. This is because there is a time lag based on the velocity difference, which prevents the particles from colliding with the oscillating plate (see Fig. 12(b)).

Fig. 14 shows the probability of particle collision with the plate moving upward to the total number of collisions as a function of the vertical incident velocity, which was obtained from the integration of Eqs. (1) or (2) in the region that the plate is moving upward $(\pi / 2<\varphi<3 \pi / 2)$. For higher incident velocities, the probability approaches 0.5 because the effect of the plate oscillation is relatively insignificant. At smaller incident velocities (less than $100 \mathrm{~mm} / \mathrm{s}$ ), the collision probability drastically increases with decreasing velocity. Therefore, the larger particles with higher incident velocity collide with the plate moving both downward and upward. The agglomerated particles with velocities less than $45 \mathrm{~mm} / \mathrm{s}$ collide with the plate moving upward with higher probabilities.

\subsection{Effect of particle diameter on transport velocity}

To discuss the effect of particle diameter on the transport velocity, the average horizontal velocities during each bounce were calculated from the data for 200 bounces. Fig. 15 shows the cumulative distributions of the average horizontal velocities for three different-sized particles. The positive and negative values of the horizontal velocities indicate forward and backward bounces, respectively. The horizontal velocity distributions of particles with $D_{p 50}=500 \mu \mathrm{m}, 50 \mu \mathrm{m}$, and $0.5 \mu \mathrm{m}\left(D_{a g 50}=150 \mu \mathrm{m}\right)$ had ranges of $-50-60$ $\mathrm{mm} / \mathrm{s},-20-40 \mathrm{~mm} / \mathrm{s}$, and 0-60 mm/s, respectively, and median velocities of $18 \mathrm{~mm} / \mathrm{s}, 14 \mathrm{~mm} / \mathrm{s}$, and 23 $\mathrm{mm} / \mathrm{s}$. The ratios of the backward bounces to the total number of bounces for $D_{p 50}=500 \mu \mathrm{m}, 50 \mu \mathrm{m}$, and $D_{a g 50}=150 \mu \mathrm{m}$ are $0.3,0.1$, and 0, respectively. The agglomerated particles always bounced forward in this measurement because they collide with the plate moving upward with higher probabilities as shown in Section 3.5. As a result, the agglomerated particles had the highest transport velocity among these differentsized particles.

\section{Conclusions}

The saltation of different-sized particles on an obliquely oscillating plate was analyzed through microscopic observation and a theoretical approach. The main findings of this study can be summarized as follows:

(1) The particles with a mass median diameter of $D_{p 50}=500 \mu \mathrm{m}$ and $50 \mu \mathrm{m}$ saltated individually on the obliquely oscillating plate. The particles with $D_{p 50}=50 \mu \mathrm{m}$ saltated at a height range several times lower than that of the particles with $D_{p 50}=500 \mu \mathrm{m}$ as a result of the effects of the fluid resistance during the bounces into the air. For $D_{p 50}=5 \mu \mathrm{m}$, the particles adhered to the oscillating plate and could not saltate owing to the adhesive forces. The particles with $D_{p 50}=0.5 \mu \mathrm{m}$ formed agglomerated particles with $D_{a g 50}=$ 
$150 \mu \mathrm{m}$ as a result of their cohesive forces, and the agglomerated particles bounced only slightly because of the low restitution of their loosely packed structure.

(2) The particles with $D_{p 50}=500 \mu \mathrm{m}$ and $50 \mu \mathrm{m}$ were transported by the repeated bounces, with motions both forward and backward. The ratio of bounces moving backward to the total bounces decreased with decreasing primary particle diameter. For the agglomerated particles with $D_{a g 50}=150 \mu \mathrm{m}$, the ratio of the backward bounces was zero. The difference between these ratios can be explained as follows. Higher bounces of larger particles cause larger impulses at particle-plate collisions. The larger impulses induce larger horizontal forces and consequently change the horizontal velocity of the particle. In addition, the particle colliding with the obliquely oscillating plate moving upward and downward results in motion forward and backward. On the other hand, when the incident particle velocity is lower than the plate velocity, the particle cannot approach the plate moving downward but can collide with it moving upward. From an analysis based on a theoretical probability model, it was found that the agglomerated particles with low incident velocity rarely collide with the plate moving downward.

(3) The agglomerated particles always bounced forward, and consequently had the highest transport velocity among these different-sized particles.

\section{Acknowledgments}

This work was supported by JSPS KAKENHI Grant Number 25-1710. The authors acknowledge the financial support. In addition, the authors are thankful to Taimei Chemicals Co., Ltd. and Fujimi Incorporated for providing particles.

\section{References}

[1] C. Laroche, S. Douady, S. Fauve, Convective flow of granular masses under vertical vibrations, J. Phys. (Paris) 50 (1989) 699-706.

[2] Y-h. Taguchi, New origin of a convective motion: Elastically induced convection in granular materials, Phys. Rev. Lett. 69 (1992) 1367-1370.

[3] J. A. C. Gallas, H. J. Herrmann, S. Sokolowski, Convection cells in vibrating granular media, Phys. Rev. Lett. 69 (1992) 1371-1374.

[4] H. K. Pak, P. R. Behringer, Bubbling in vertically vibrated granular materials, Nature (London) 371 (1994) 231-233.

[5] P. Zamankhan, Bubbles and solid structures in a vibrated bed of granular materials, Physica A 390 (2011) 1402-1416.

[6] P. Zamankhan, Bubbling in vibrated granular films, Phys. Rev. E 83 (2011) 021306.

[7] J. B. Knight, H. M. Jaeger, S. R. Nagel, Vibration-induced size separation in granular media: The convection connection, Phys. Rev. Lett. 70 (1993) 3728-3731. 
[8] W. Cooke, S. Warr, J. M. Huntley, R. C. Ball, Particle size segregation in a two-dimensional bed undergoing vertical vibration, Phys. Rev. E 53 (1996) 2812-2822.

[9] A. Kudrolli, Size separation in vibrated granular matter, Rep. Prog. Phys. 67 (2004) 209-247.

[10] S. Matsusaka, M. Kobayakawa, M. Mizutani, M. Imran, M. Yasuda, Bubbling behavior of a fluidized bed of fine particles caused by vibration-induced air inflow, Sci. Rep. 3 (2013) 1190.

[11] J. R. Wank, S. M. George, A. W. Weimer, Vibro-fluidization of fine boron nitride powder at low pressure. Powder Technol. 121 (2001) 195-204.

[12] C. H. Nam, R. Pfeffer, R. N. Dave, S. Sundaresan, Aerated vibrofluidization of silica nanoparticles, AIChE J. 50 (2004) 1776-1785.

[13] E. M. Sloot, N. P. Kruyt, Theoretical and experimental study of the transport of granular materials by inclined vibratory conveyors, Powder Technol. 87 (1996) 203-210.

[14] R. Grochowski, P. Walzel, M. Rouijaa, C. A. Kruelle, I. Rehberg, Reversing granular flow on a vibratory conveyor, Appl. Phys. Lett. 84 (2004) 1019-1021.

[15] S. Matsusaka, M. Urakawa, H. Masuda, Micro-feeding of fine powders using a capillary tube with ultrasonic vibration, Adv. Powder Technol. 6 (1995) 283-293.

[16] S. Matsusaka, K. Yamamoto, H. Masuda, Micro-feeding of a fine powder using a vibrating capillary tube, Adv. Powder Technol. 7 (1996) 141-151.

[17] Y. Jiang, S. Matsusaka, H. Masuda, Y. Qian, Development of measurement system for powder flowability based on vibrating capillary method, Powder Technol. 188 (2009) 242-247.

[18] K. Ishii, M. Suzuki, T. Segawa, Y. Kihara, M. Yasuda, S. Matsusaka, A vibrating tube method for evaluating flowability of a small amount of sample particles, Adv. Powder Technol. 22 (2011) 522-525.

[19] I. M. Zainuddin, M. Yasuda, T. Horio, S. Matsusaka, Exeperimental study on powder flowability using vibration shear tube method, Part. Part. Syst. Char. 29 (2012) 8-15.

[20] E. Clement, S. Luding, A. Blumen, J. Rajchenbach, J. Duran, Fluidization, condensation and clusterization of a vibrating column of beads, J. Mod. Phys. B 7 (1993) 1807-1827.

[21] S. Luding, E. Clement, A. Blumen, J. Rajchenbach, J. Duran, Studies of columns of beads under external vibrations, Phys. Rev. E 49 (1994) 1634-1646.

[22] J. -C. Germinard, C. Laroche, Energy of a single bead bouncing on a vibrating plate: Experiments and numerical simulations, Phys. Rev. E 68 (2003) 031305.

[23] J. J. Barroso, M. V. Carneiro, E. E. N. Macau, Bouncing ball problem: Stability of the periodic modes, Phys. Rev. E 79 (2009) 026206.

[24] M. Iijima, M. Kobayakawa, M. Yamazaki, Y. Ohta, H. Kamiya, Anionic surfactant with hydrophobic and hydrophilic chains for nanoparticle dispersion and shape memory polymer nanocomposites, J. Am. Chem. Soc. 131 (2009) 16342-16343.

[25] D. A. Gorham, A. H. Kharaz, The measurement of particle rebound characteristics, Powder Technol. 112 (2000) 193-202. 
[26] A. H. Kharaz, D. A. Gorham, A. D. Salman, An experimental study of the elastic rebound of spheres, Powder Technol. 120 (2001) 281-291.

[27] C. C. Feng, K. F. Graff, Impact of a spherical tool against a sonic transmission line, J. Acoust. Soc. Am. 52 (1972) 254-259.

[28] L. A. Wood, K.P. Byrne, Analysis of a random repeated impact process, J. Sound Vib. 78 (1981) 329345.

[29] J. M. Luck, A. Mehta, Bouncing ball with a finite restitution: Chattering, locking, and chaos, Phys. Rev. E 48 (1993) 3988-3997.

[30] S. Warr, J. M. Huntley, Energy input and scaling laws for a single particle vibrating in one dimension, Phys. Rev. E 52 (1995) 5596-5601.

\section{Table 1}

Physical properties of the different-sized particles.

\begin{tabular}{cccc}
\hline Particle diameter $D_{p 50}(\mu \mathrm{m})$ & 500 & 50 & $0.5\left(D_{a g 50}=150 \mu \mathrm{m}\right)$ \\
\hline Particle density $\rho_{p}\left(\mathrm{~kg} / \mathrm{m}^{3}\right)$ & 3900 & 3900 & 930 \\
Coefficient of restitution $e(-)$ & 0.9 & 0.9 & 0.1 \\
Coefficient of friction $\mu(-)$ & 0.1 & 0.1 & 0.2 \\
\hline
\end{tabular}

Table 2

Velocity variations during collision and bounce.

\begin{tabular}{cccc}
\hline Particle diameter $D_{p 50}(\mu \mathrm{m})$ & 500 & 50 & $0.5\left(D_{a g 50}=150 \mu \mathrm{m}\right)$ \\
\hline$v_{n r} / v_{n i}$ & $0.5-1.4$ & $0.6-2.1$ & $0.9-1.7$ \\
$v_{(n+1) i} / v_{n r}$ & 1.0 & $0.6-0.8$ & $0.7-0.8$ \\
\hline
\end{tabular}


Figure contents

Fig. 1. Schematic diagram of the experimental setup. Particles are distributed on a metal plate. The plate is vibrated horizontally and vertically by three piezoelectric vibrators. The two-dimensional motion of the particles and the plate is observed from one side of the plate through a high-speed microscope camera.

Fig. 2. Displacement of the oscillating plate as a function of time elapsed in (a) the horizontal direction and (b) the vertical direction. The data were obtained from the images captured by the high-speed microscope camera at a frame rate of $6000 \mathrm{fps}$. The signals applied to the piezoelectric vibrators were sine waves with a frequency of $280 \mathrm{~Hz}$ and the phase difference between the waves was zero.

Fig. 3. A Lissajous figure of the obliquely oscillating plate. The wave data of ten cycles are shown here.

Fig. 4. (a) SEM image of agglomerated particle, (b) Magnified image of the agglomerated particle.

Fig. 5. Snapshots of particle saltation on the obliquely oscillating plate for (a) $D_{p 50}=500 \mu \mathrm{m}$, (b) $D_{p 50}=50$ $\mu \mathrm{m}$, and (c) $D_{p 50}=0.5 \mu \mathrm{m}$. The images were captured by the high-speed microscope camera at a frame rate of 6000 fps. Primary particles were bouncing (in Figs. 5(a) and (b)), and agglomerated particles with $D_{a g 50}$ $=150 \mu \mathrm{m}$ were bouncing only slightly (in Fig. 5(c)).

Fig. 6. Trajectories of particles tracked by digital image processing for (a) $D_{p 50}=500 \mu \mathrm{m}$, (b) $D_{p 50}=50 \mu \mathrm{m}$, and (c) $D_{p 50}=0.5 \mu \mathrm{m}\left(D_{a g 50}=150 \mu \mathrm{m}\right)$. The value of zero in the vertical displacement indicates the center of the oscillation. Solid and dashed lines indicate bounces moving forward and backward, and circles denote the collision of the particles with the oscillating plate.

Fig. 7. Cumulative distributions of bounce heights. Each distribution curve consists of 200 bounces.

Fig. 8. Cumulative distributions of bounce distances. Each distribution curve consists of 200 bounces.

Fig. 9. Vertical displacements of the particles and the plate as a function of time elapsed for (a) $D_{p 50}=500$ $\mu \mathrm{m}$, (b) $D_{p 50}=50 \mu \mathrm{m}$, and (c) $D_{p 50}=0.5 \mu \mathrm{m}\left(D_{a g 50}=150 \mu \mathrm{m}\right)$. The vertical displacements of the particles correspond to the trajectories in Figs. 6(a)-(c). To quantify the state of each particle-plate collision, the magnified figures are shown under Fig. 9(a). The thick solid lines, thin solid lines, and dashed lines indicate the oscillating plate, the particle moving forward, and the particle moving backward, respectively.

Fig. 10. Vertical velocities of the particles as a function of time elapsed for (a) $D_{p 50}=500 \mu \mathrm{m}$, (b) $50 \mu \mathrm{m}$, 
and (c) $0.5 \mu \mathrm{m}\left(D_{a g 50}=150 \mu \mathrm{m}\right)$. The values of the vertical velocity were obtained from the trajectories in Figs. 6(a)-(c). The instantaneous velocities were obtained from the time derivatives of the positions between two successive images (time interval: $0.33 \mathrm{~ms}$ ).

Fig. 11. Horizontal velocities of the particles as a function of time elapsed for (a) $D_{p 50}=500 \mu \mathrm{m}$, (b) $50 \mu \mathrm{m}$, and (c) $0.5 \mu \mathrm{m}\left(D_{a g 50}=150 \mu \mathrm{m}\right)$. The values of the horizontal velocity were obtained from the trajectories in Figs. 6(a)-(c). The instantaneous velocities were obtained from the time derivatives of the positions between two successive images (time interval: $0.33 \mathrm{~ms}$ ).

Fig. 12. Illustrations of the vertical displacements of the oscillating plate as a function of phase angle and the movement of incident particles with (a) high velocity and (b) low velocity. The solid and dashed lines indicate the oscillating plate and the incident particles. The particles are fed downward at constant time intervals and the particles approach the plate at a constant velocity.

Fig. 13. Analytical results of the collision of the particles with the oscillating plate: (a) the vertical displacement of the plate as a function of phase angle and (b) the relationship between the probability density of the collision and phase angle as a parameter of vertical incident velocity. $V=44.6 \mathrm{~mm} / \mathrm{s}$ is the calculated value, which is obtained using Eqs. (3) and (4) with $\varphi_{0}=\pi / 2$.

Fig. 14. Probability of collision with the plate moving upward to the total number of collisions as a function of vertical incident velocity.

Fig. 15. Cumulative distributions of average horizontal velocities during each bounce. Each distribution curve consists of 200 bounces. 
Fig. 1.

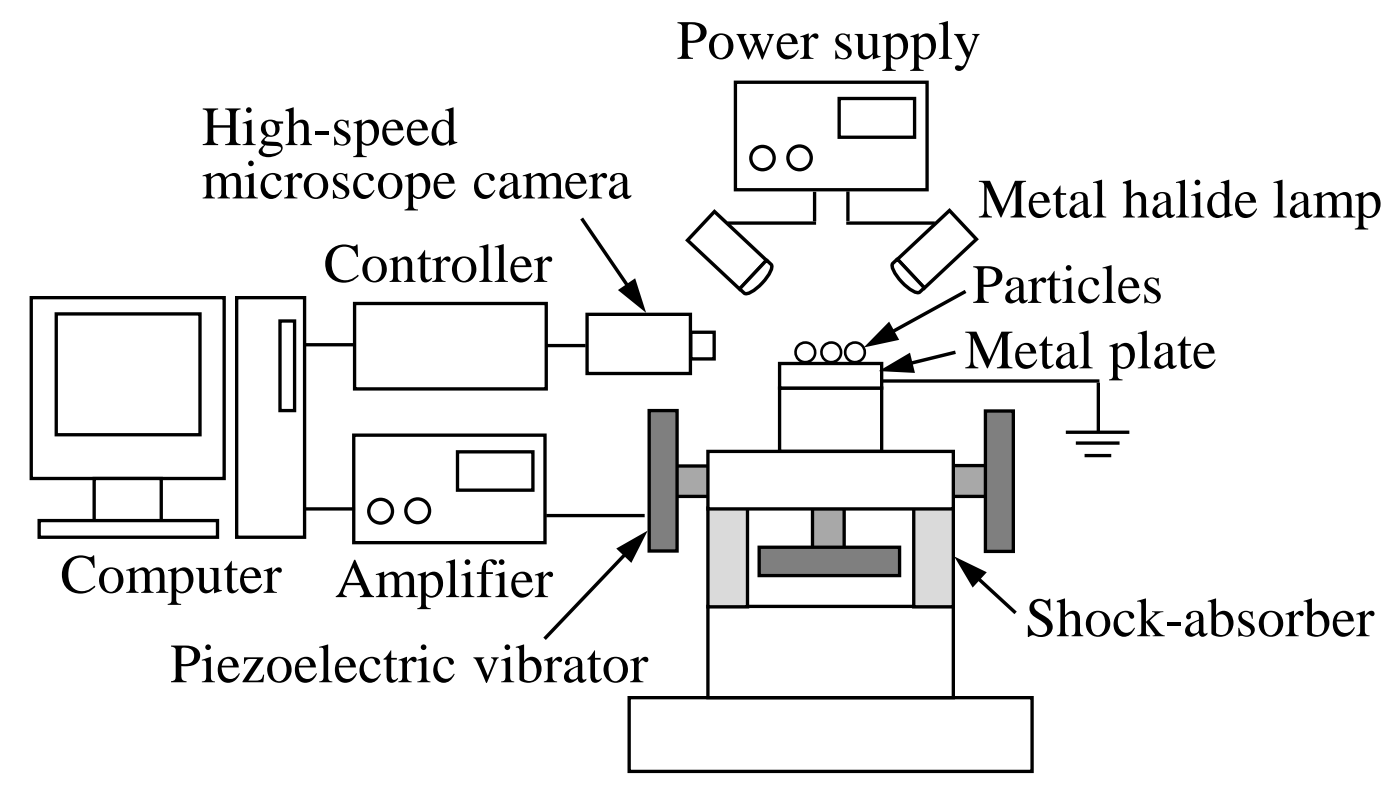


Fig. 2.

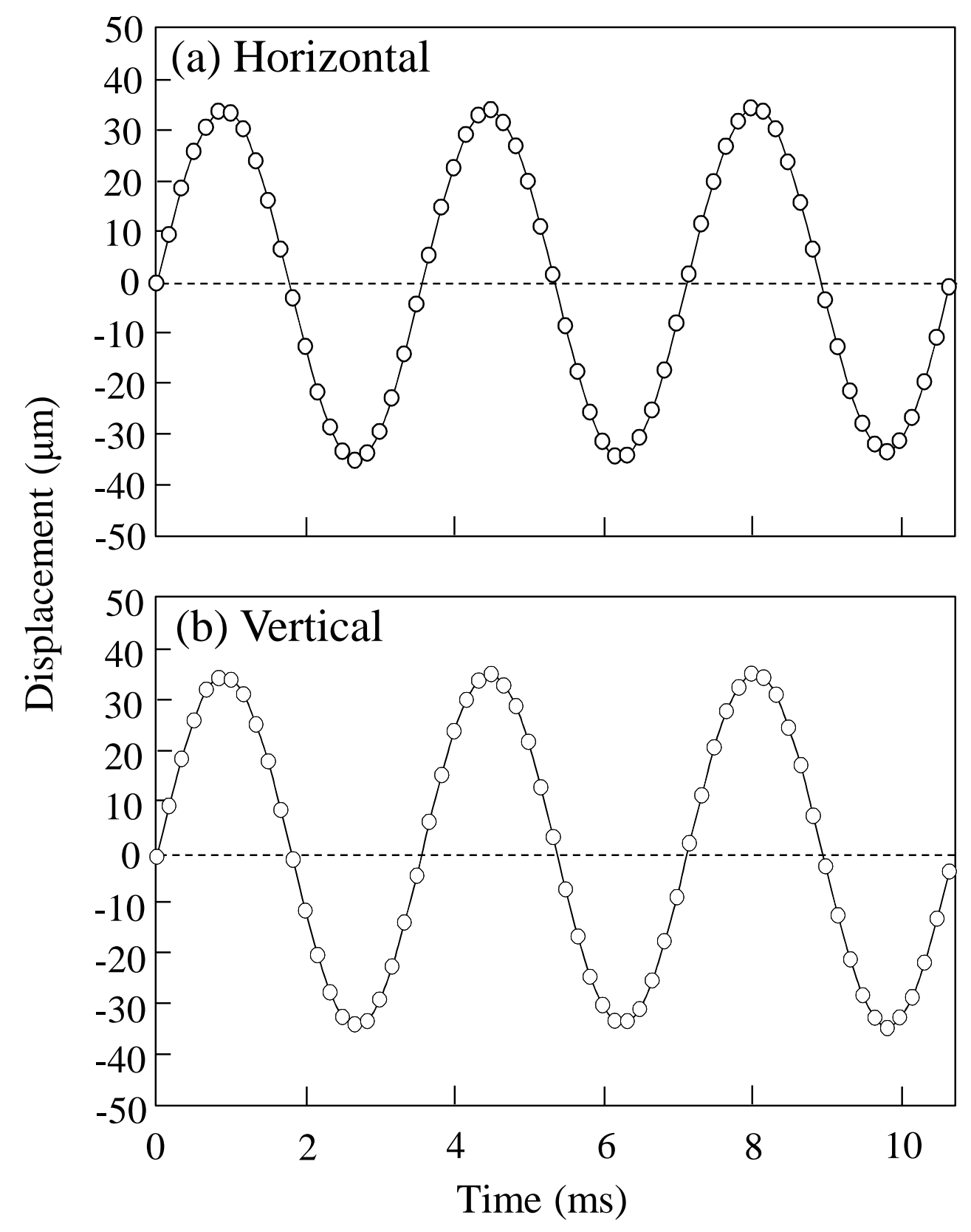


Fig. 3.

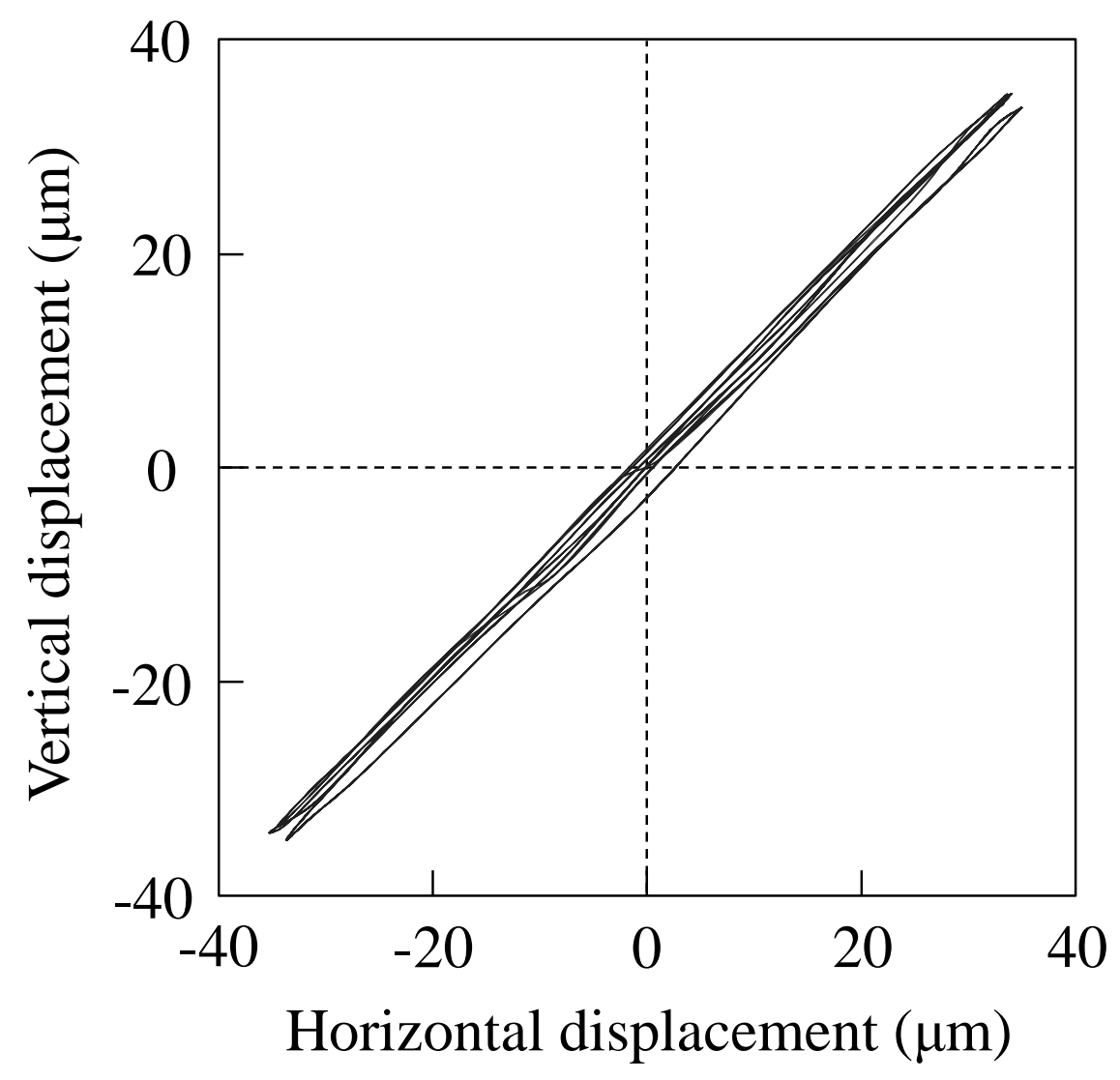


Fig. 4.

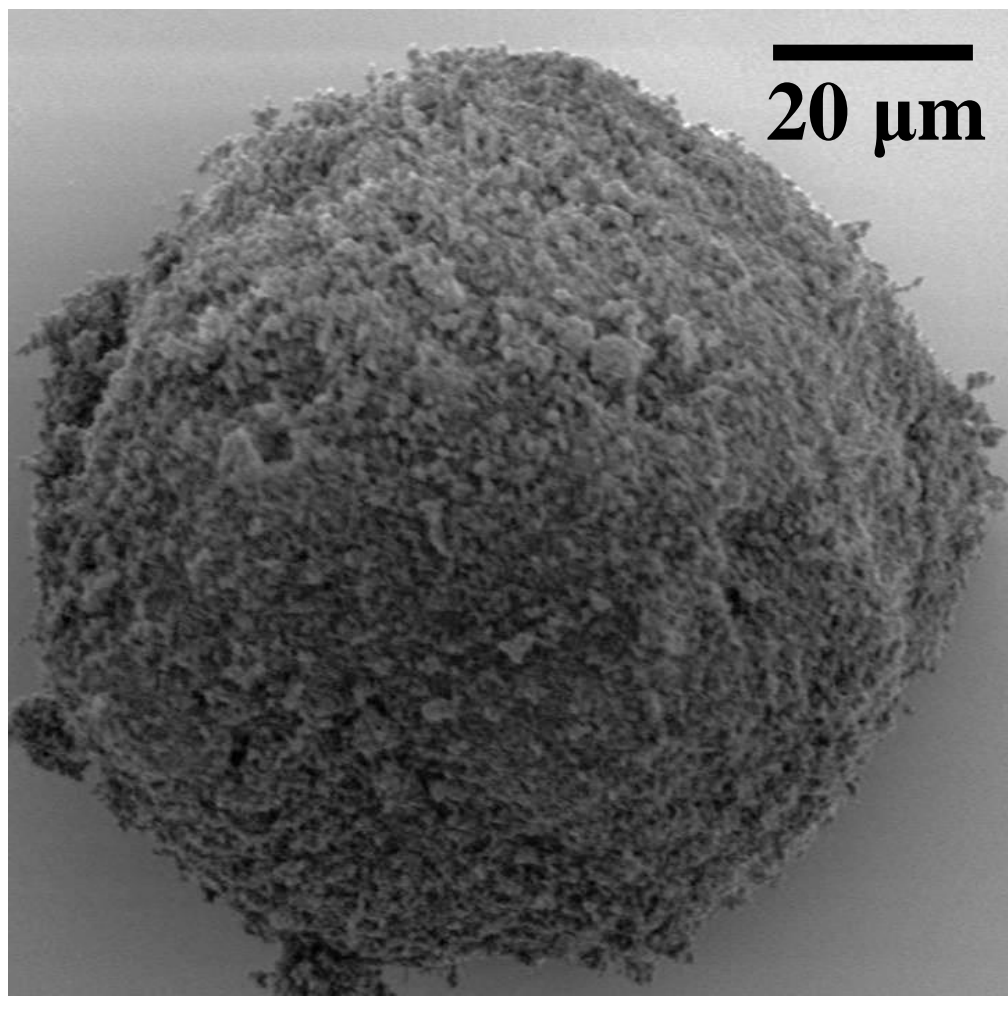

(a)

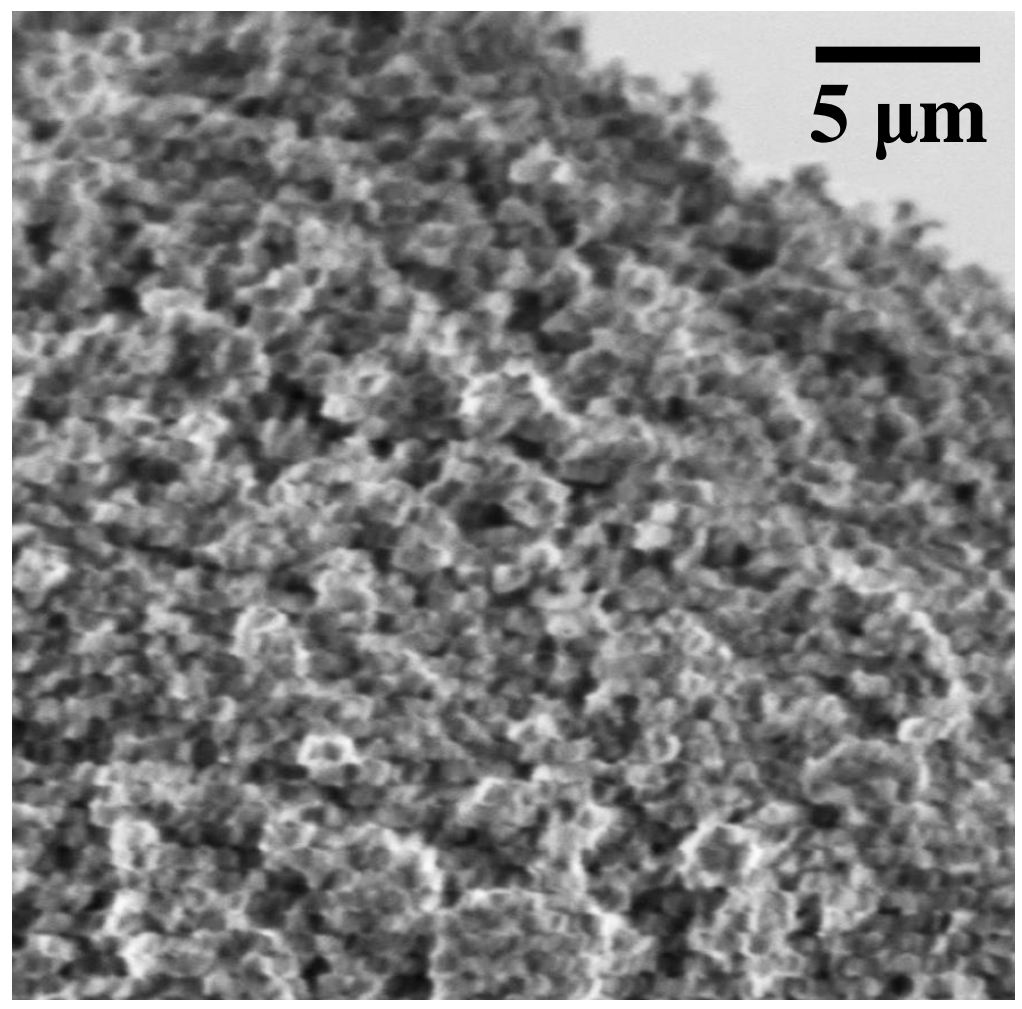

(b) 
Fig. 5.

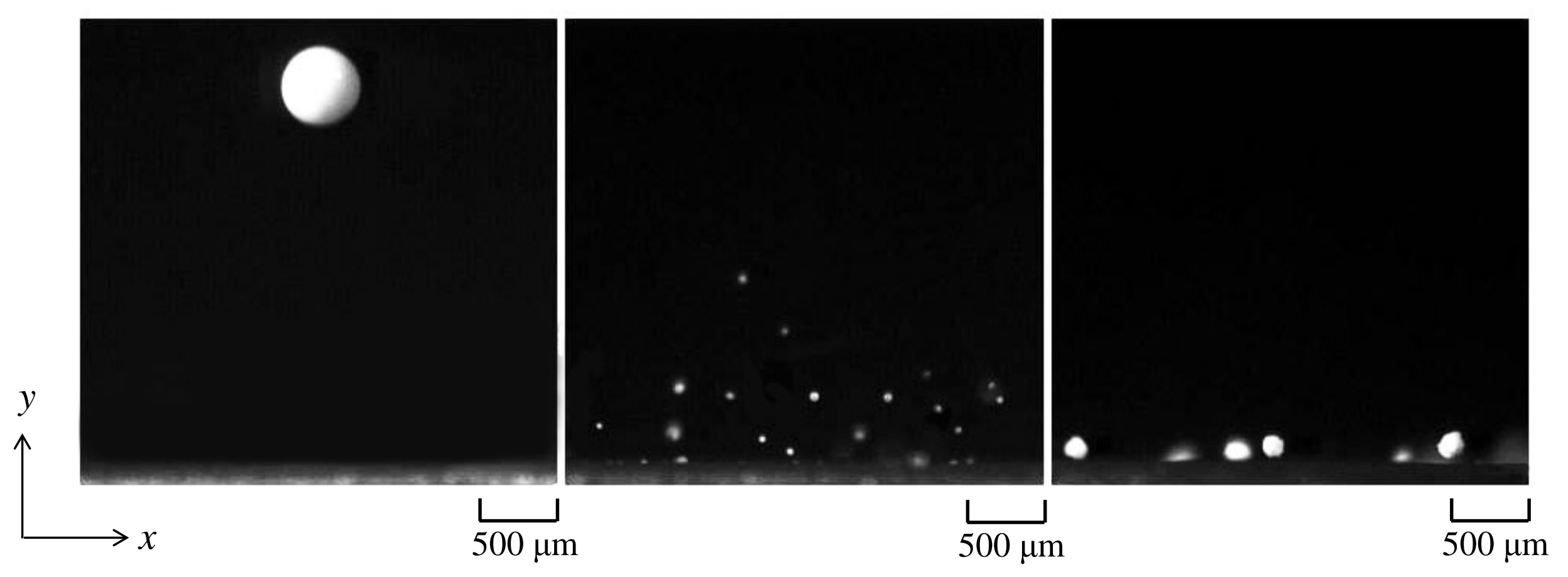
(a) $D_{p 50}=500 \mu \mathrm{m}$
(b) $D_{p 50}=50 \mu \mathrm{m}$
(c) $D_{p 50}=0.5 \mu \mathrm{m}$ 
Fig. 6.
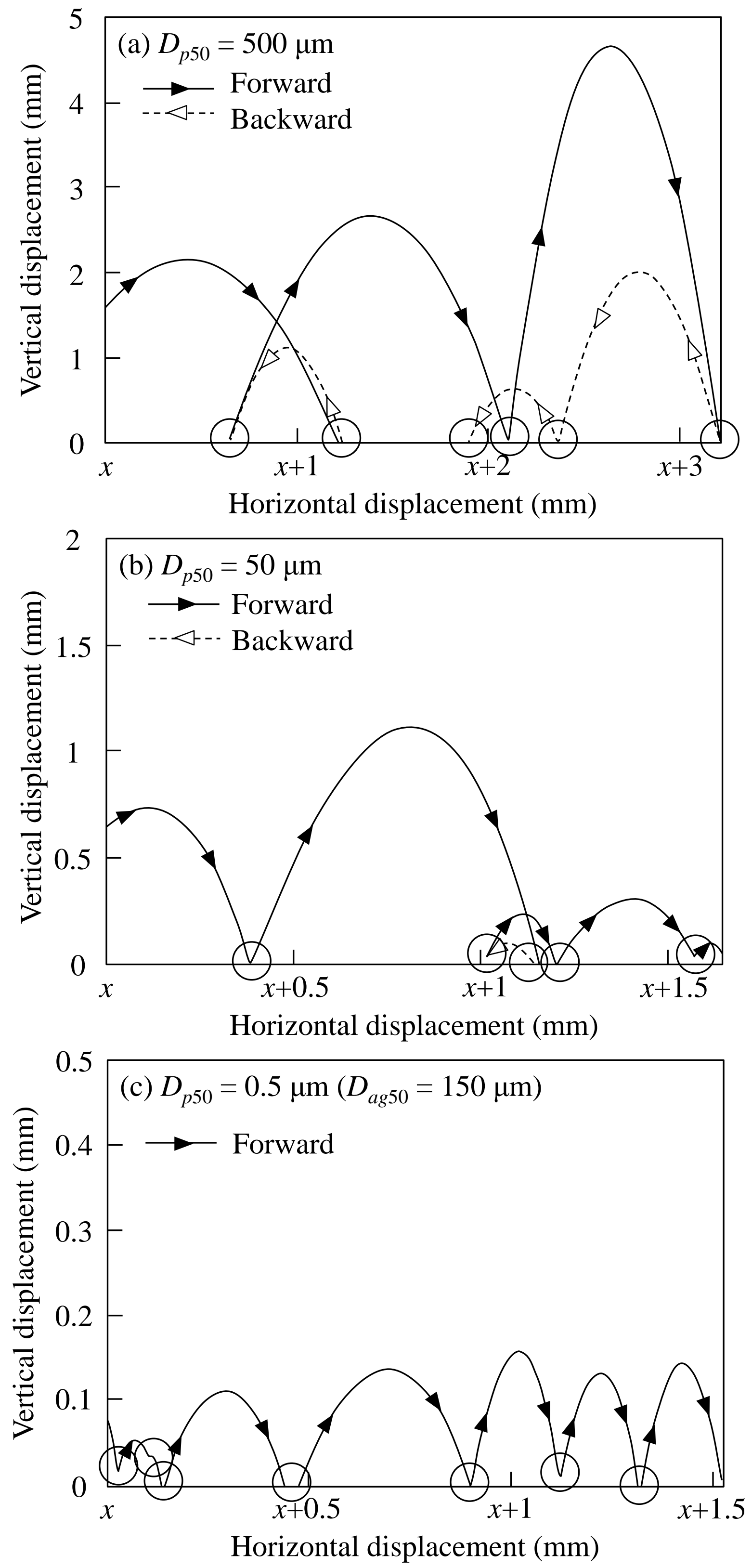


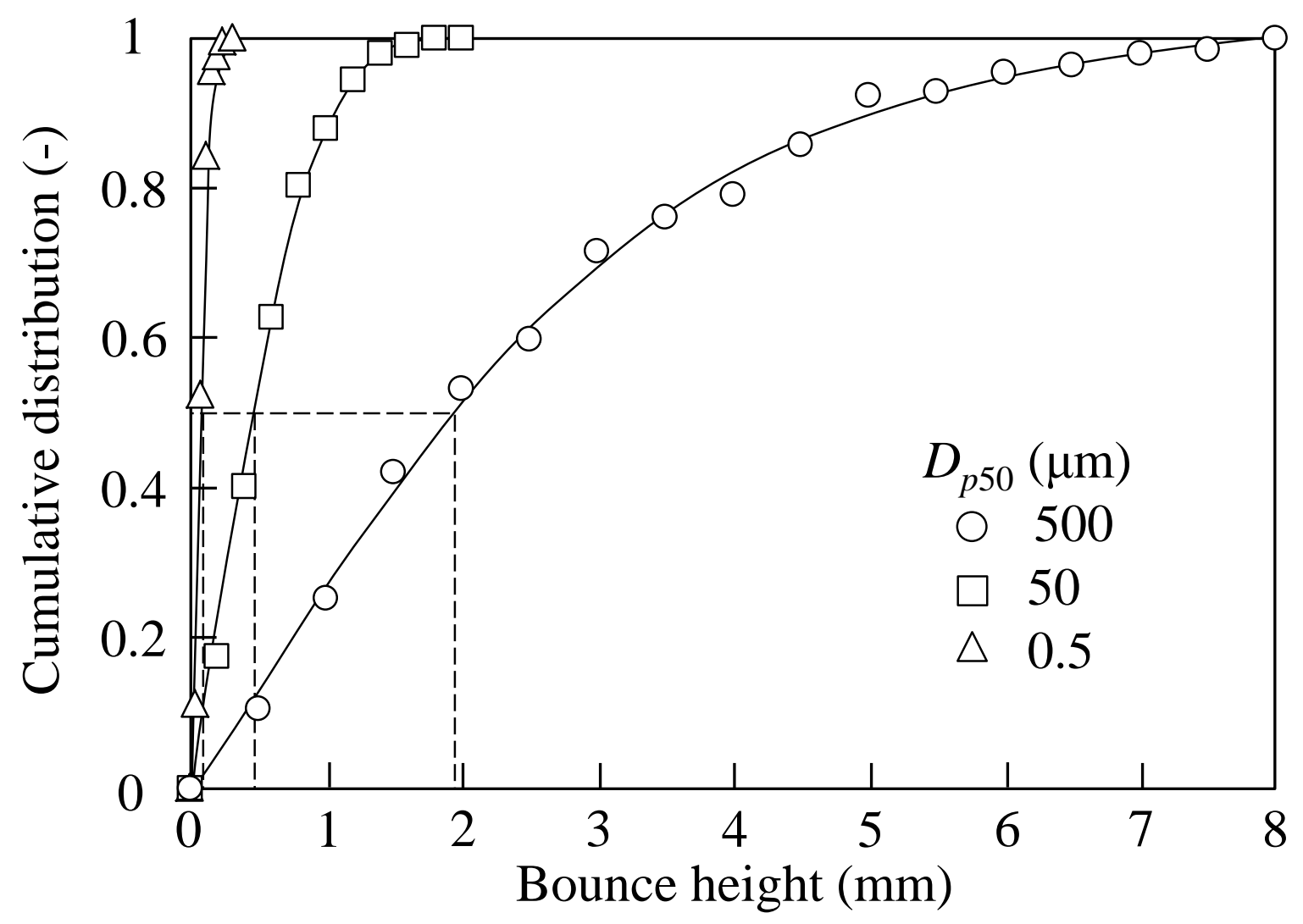


Fig. 8.

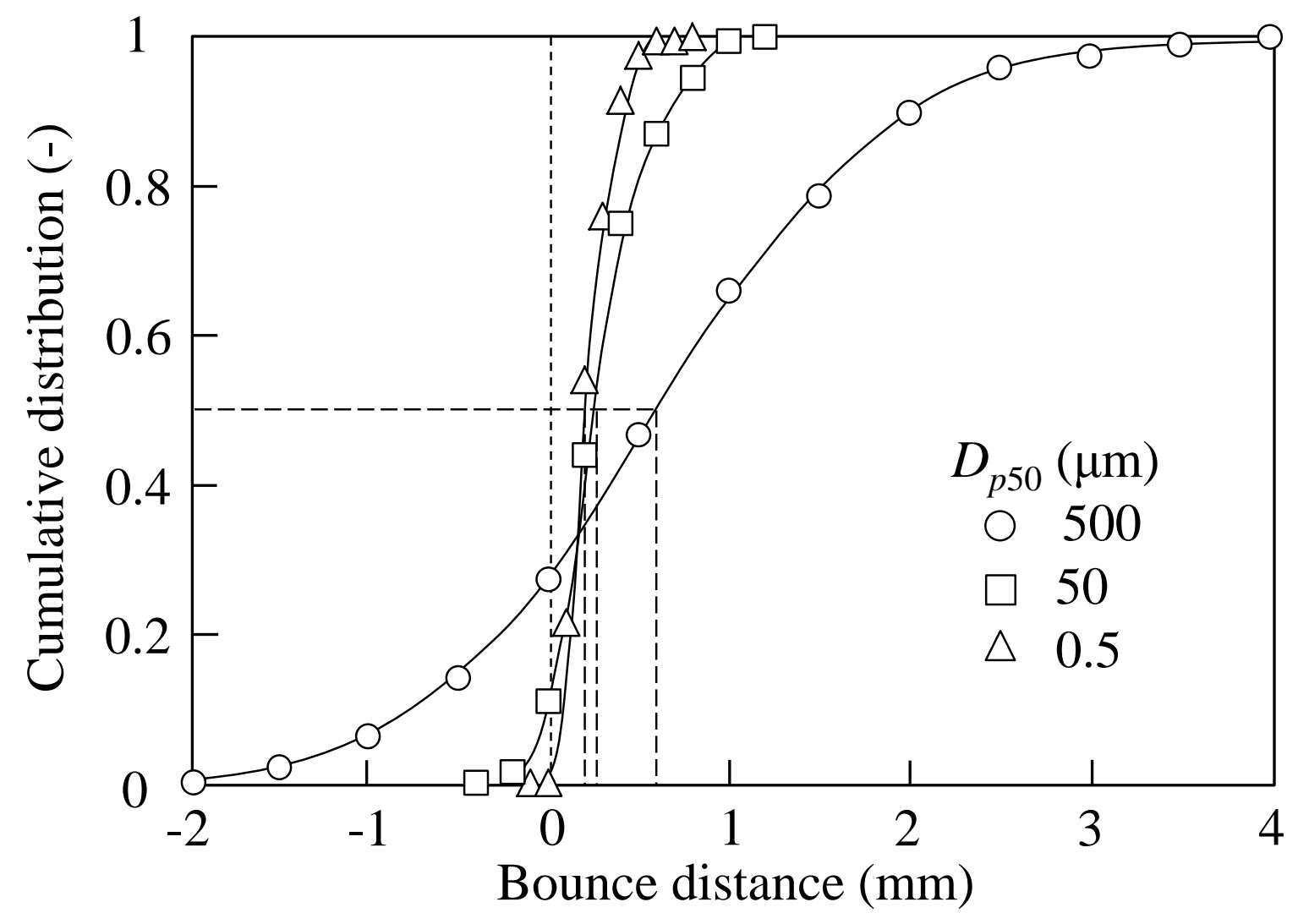


Fig. 9. (a)

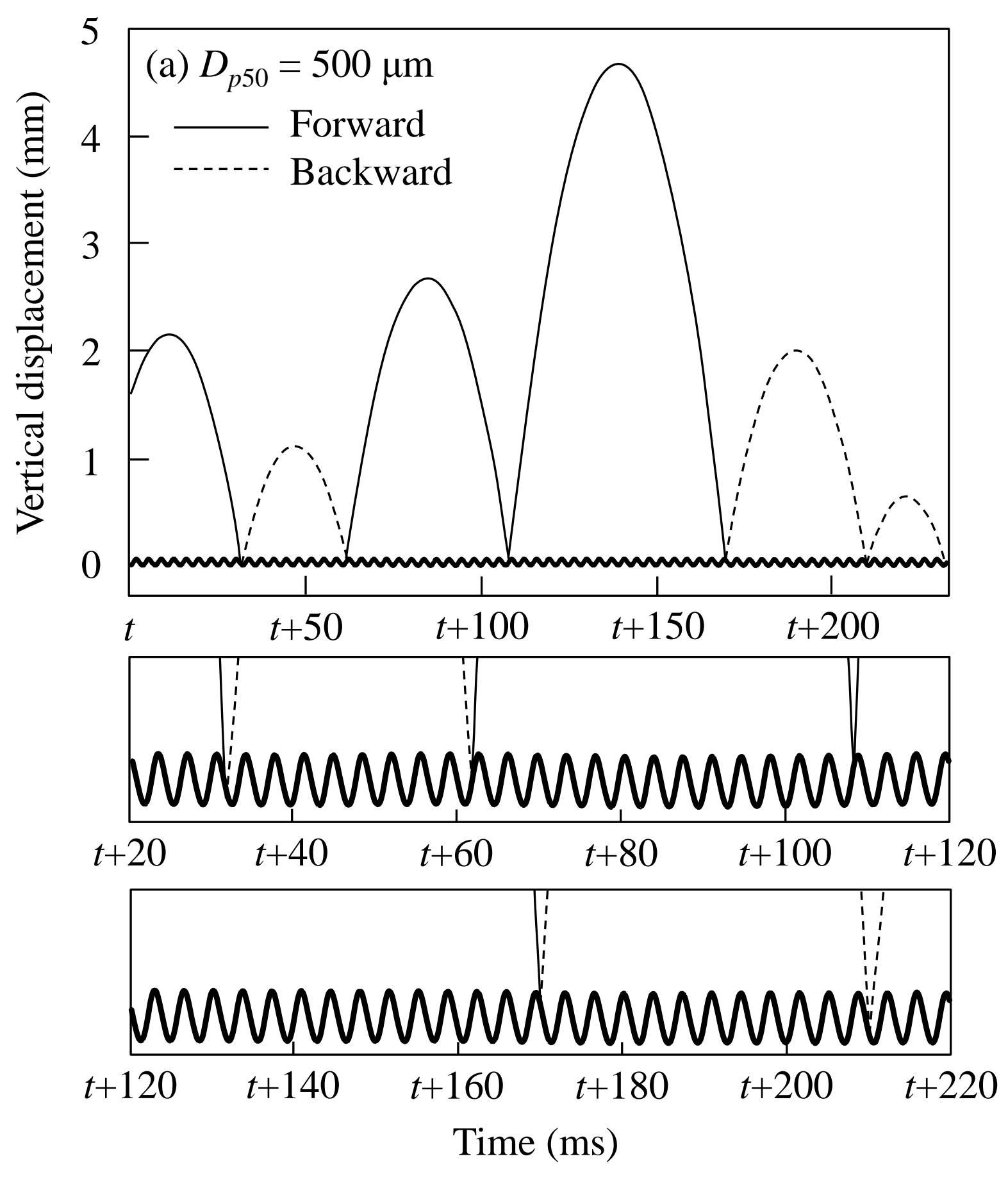


Fig. 9. (b)

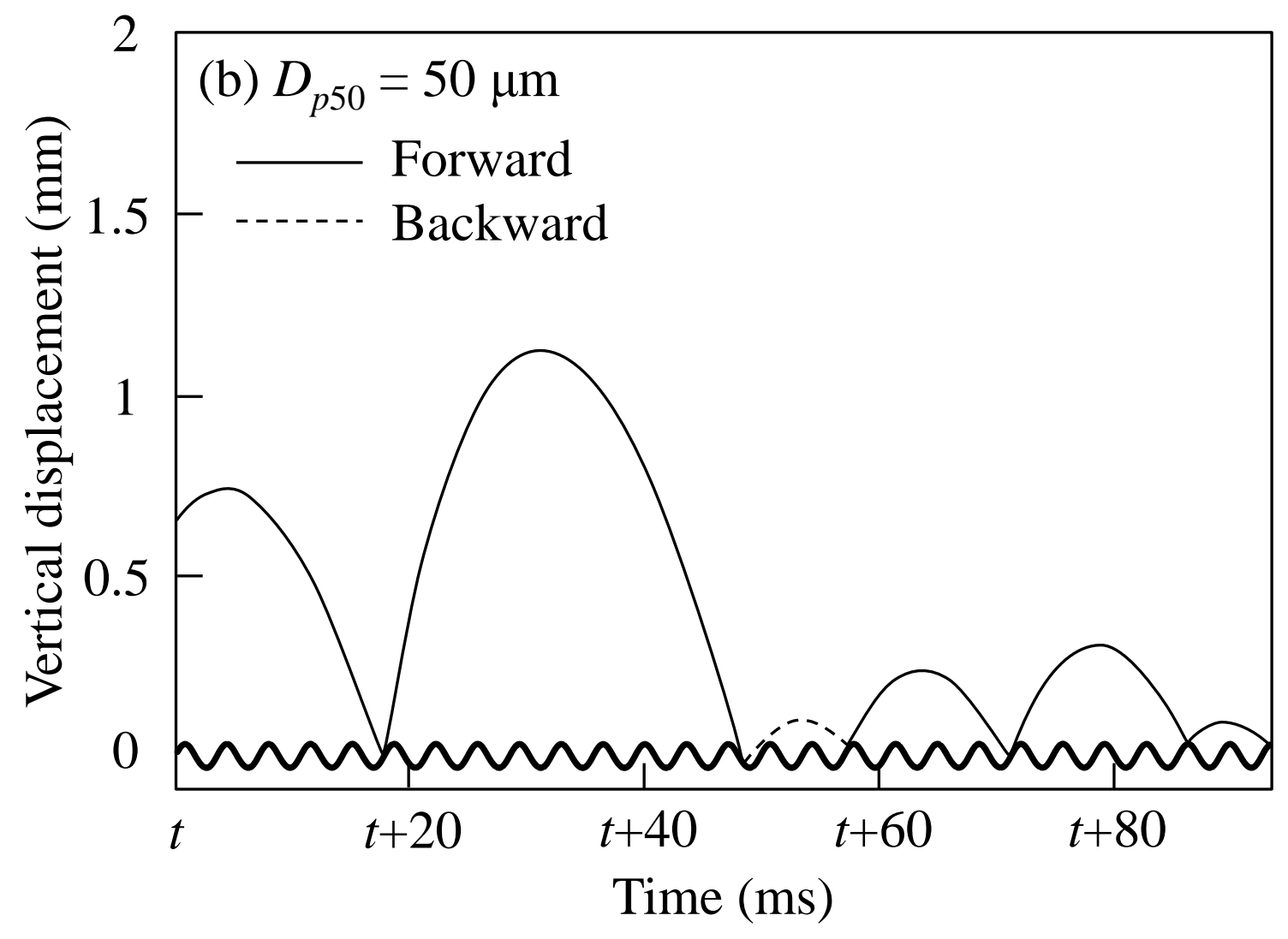


Fig. 9. (c)

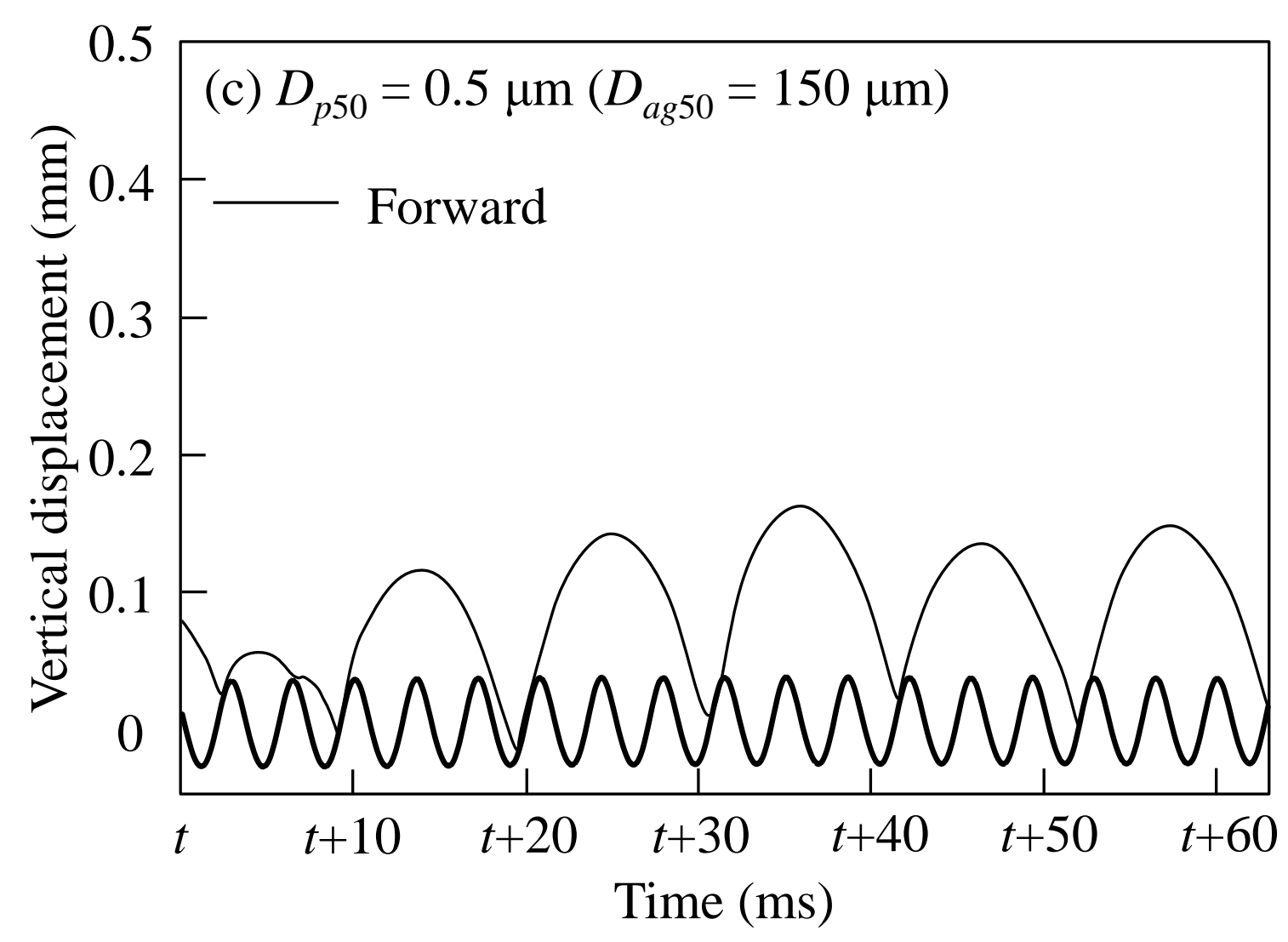


Fig. 10.
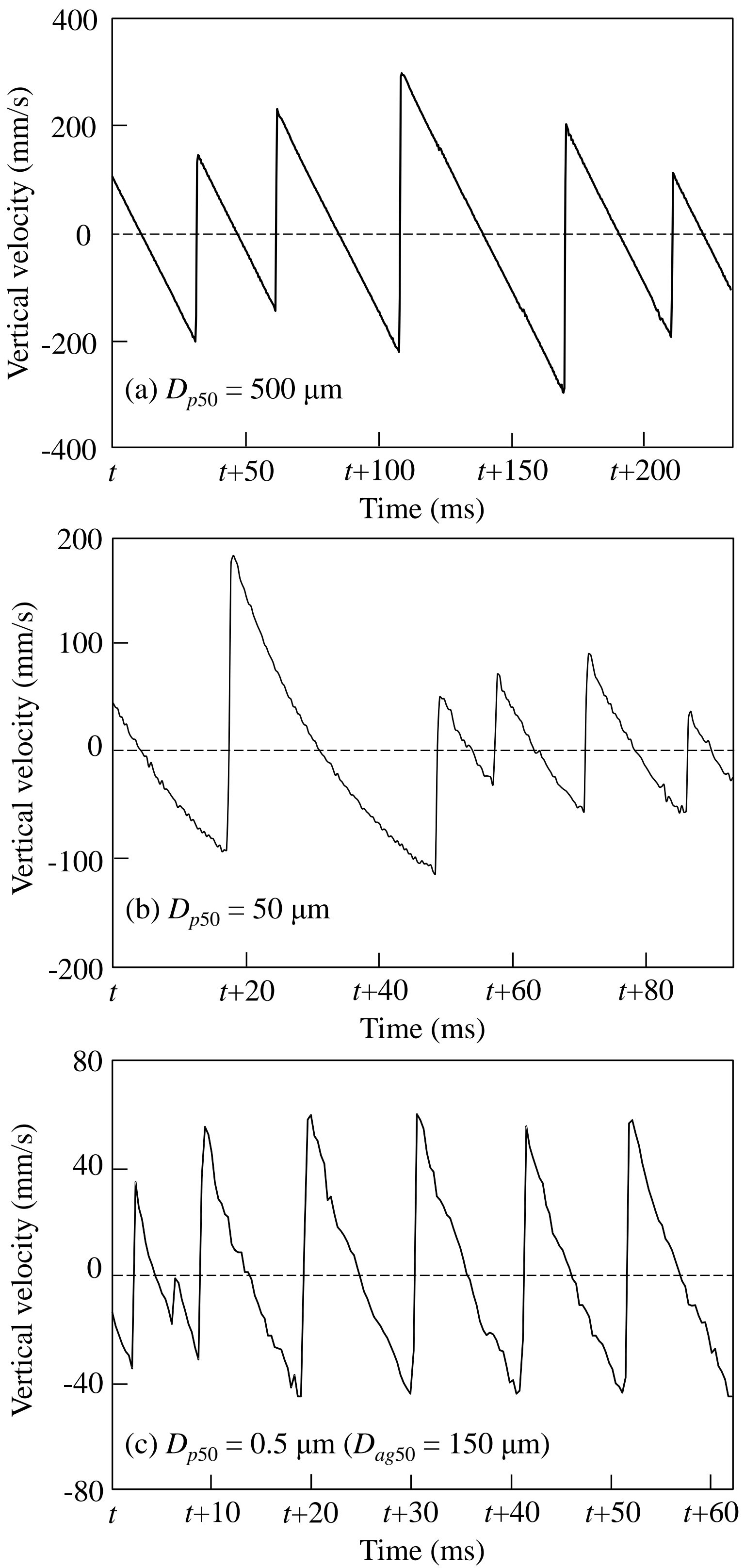
Fig. 11.
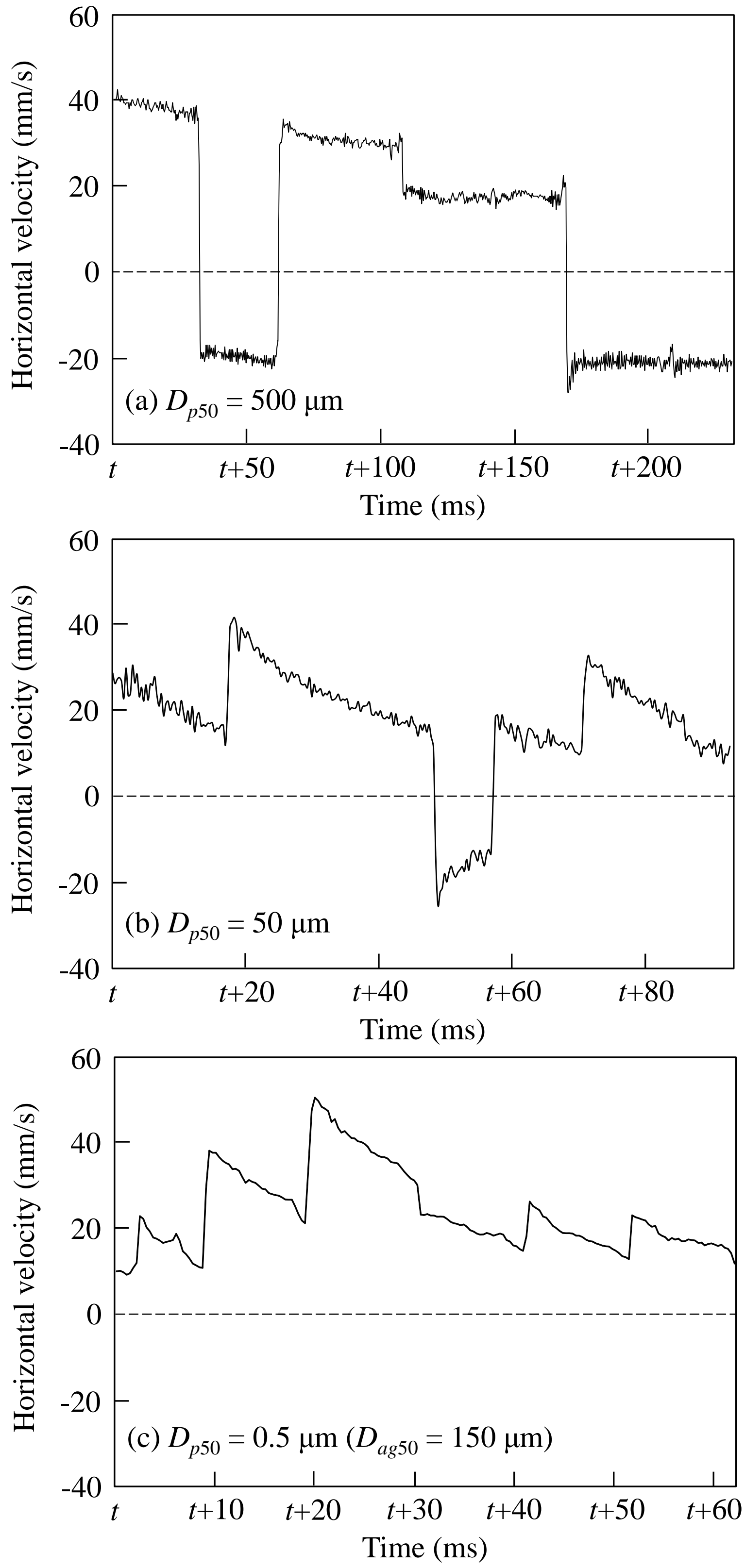
Fig. 12.

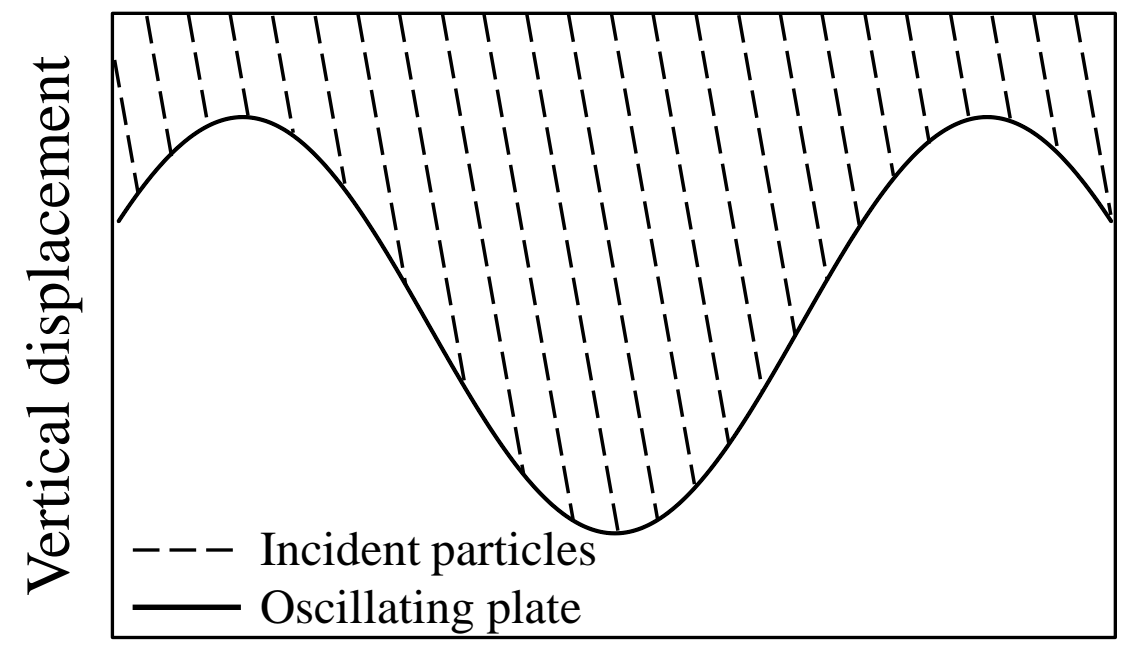

Phase angle $\varphi$

(a) Fast incident particles

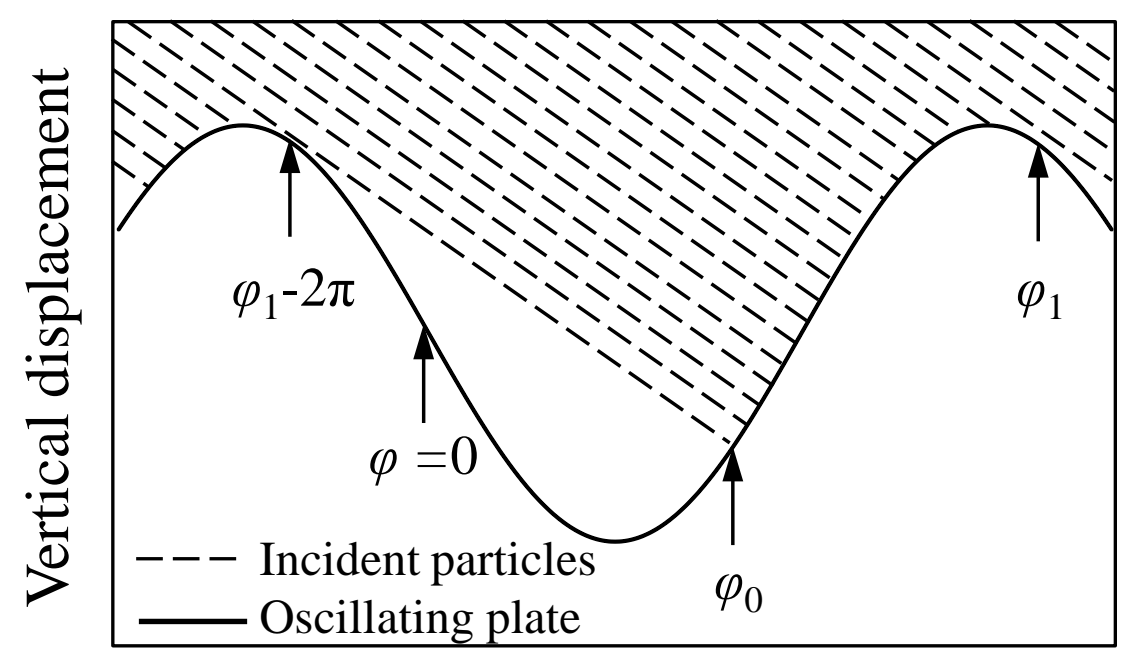

Phase angle $\varphi$

(b) Slow incident particles 
Fig. 13.
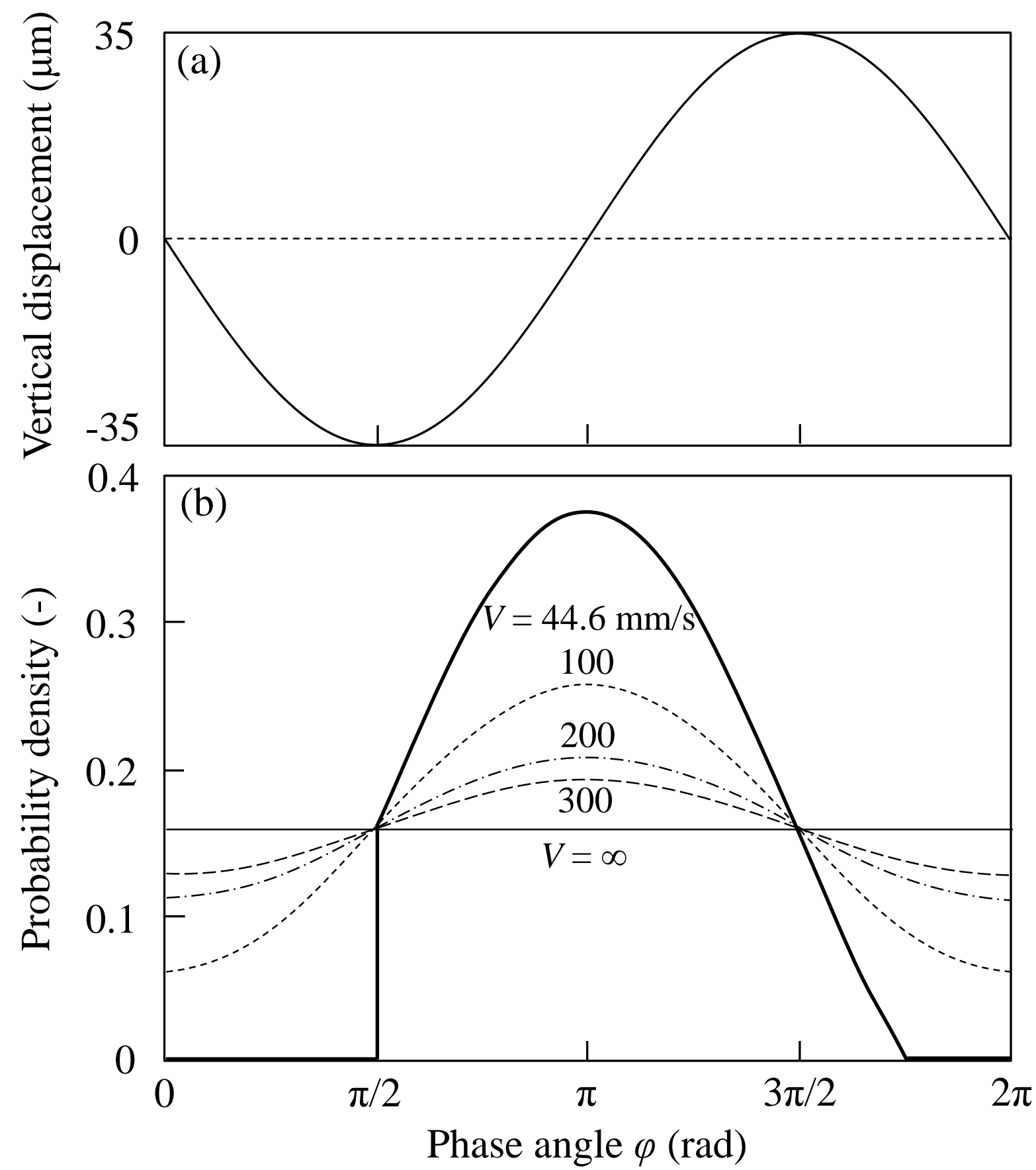
Fig. 14.

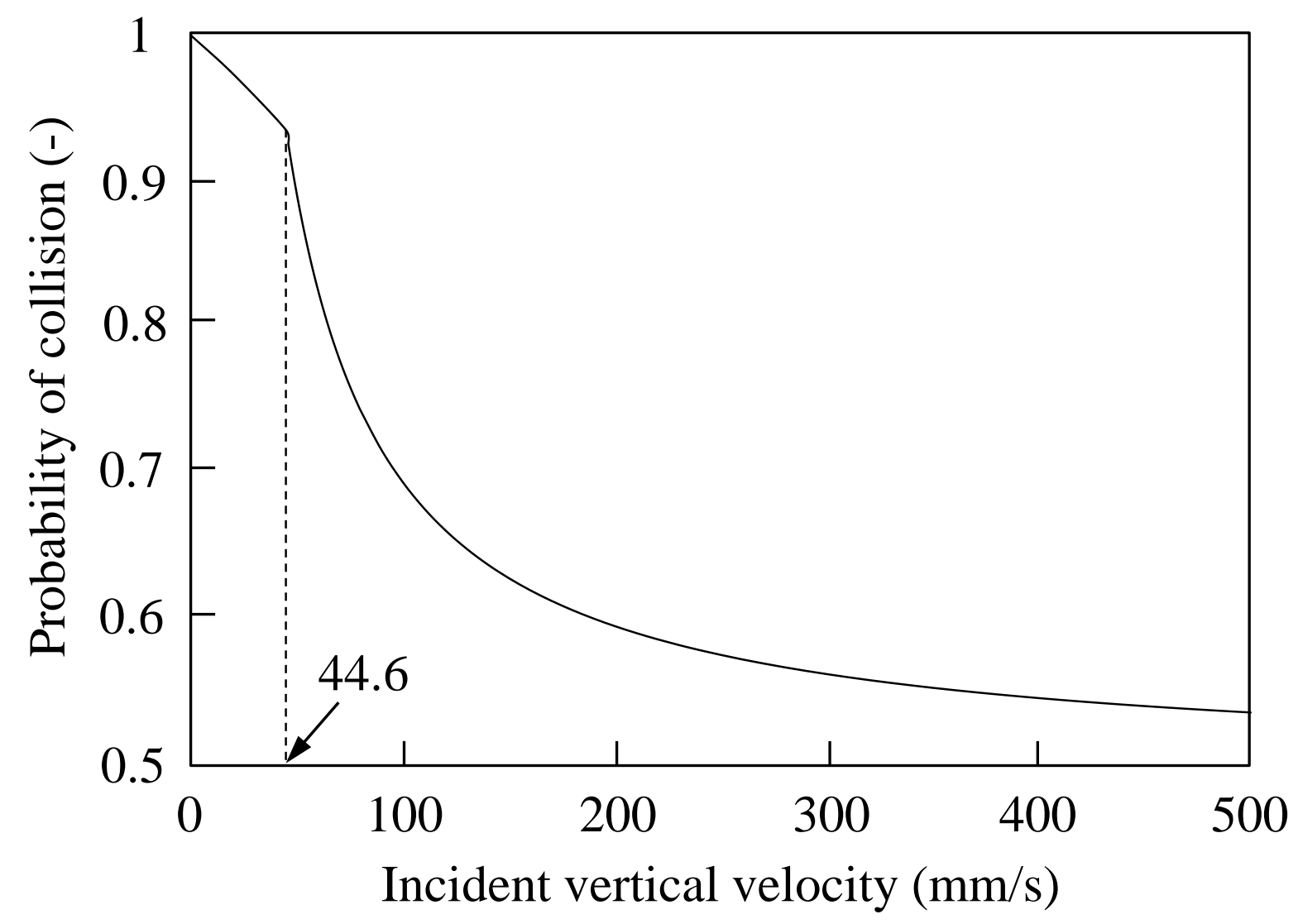


Fig. 15.

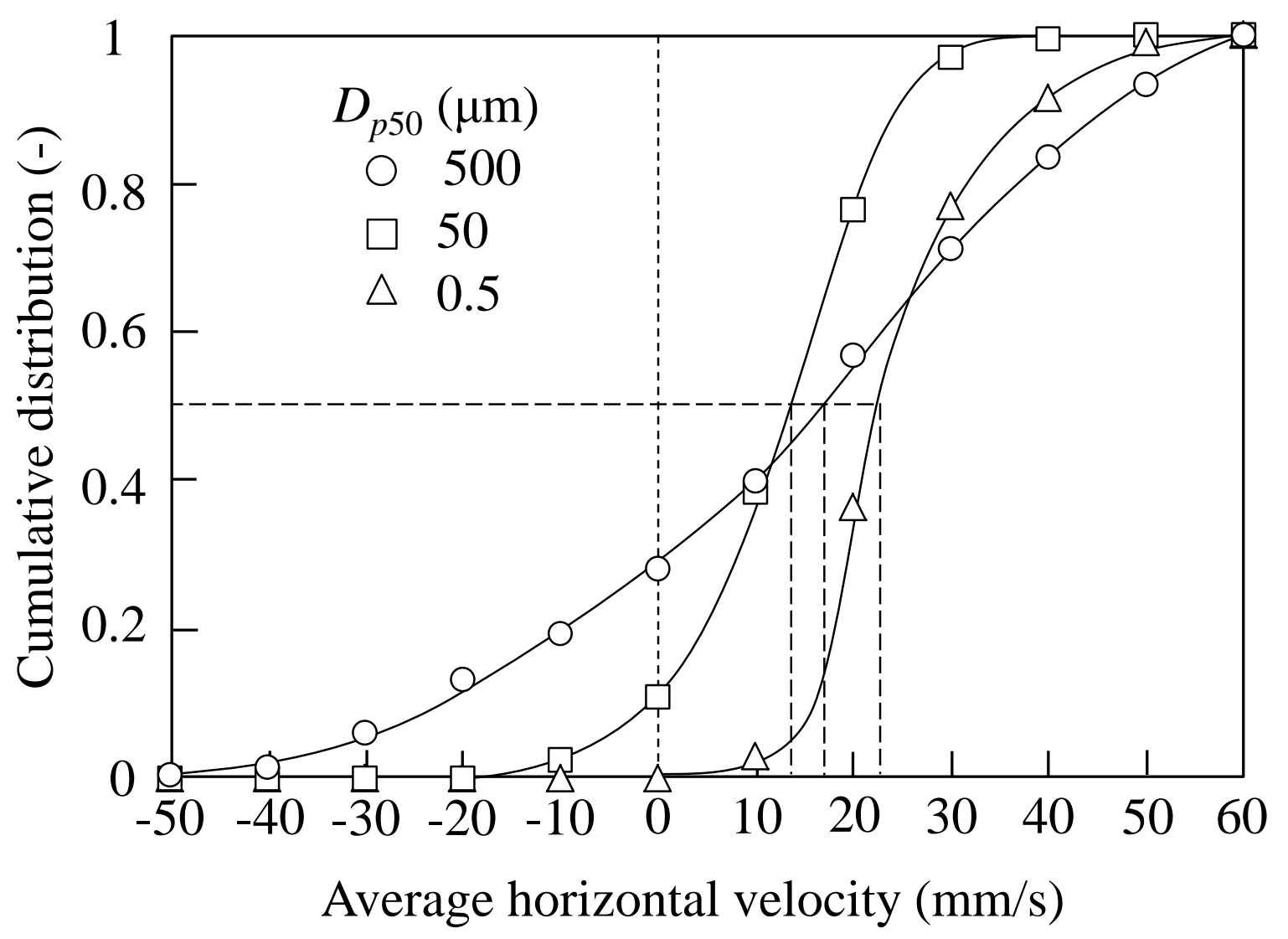

